Revista Signos 2009, 42(71) 431-446

\section{La lectura y el lector estratégicos: Hacia una tipologización ciberdiscursiva*}

La reforma de la enseñanza debe conducir a la reforma del pensamiento y la reforma del pensamiento debe conducir a la reforma de la enseñanza.

Edgar Morin (1999: 22)

\section{Lucía Fraca de Barrera \\ Universidad Pedagógica Experimental Libertador Venezuela}

\section{A modo de inicio}

Hoy en día resulta casi un lugar común señalar que las competencias referidas a la lectura y a la escritura se están transformando debido al avance de la cibernética y de las tecnologías de la información y de la comunicación. Tales eventos han traído una nueva manera de interacción: la que realiza el hombre con las máquinas. Al respecto, Cavallo y Chartier (2001: 16) han señalado que "toda historia de las prácticas de la lectura, es pues, necesariamente una historia de los objetos escritos y de las palabras lectoras". En la actualidad con la comunicación mediada por el computador se está escribiendo una nueva historia, agregamos.

Por otra parte, Edgar Morin, en el epígrafe que inicia este artículo, hace un llamado de atención en relación con la dialógica entre la enseñanza y el pensamiento. Una deriva y conlleva necesariamente cambios en el otro. En tal sentido, debemos reformar los pensamientos y las ideas para reformar postulados pedagógicos y didácticos.

Hacia estas direcciones queremos orientar este texto: señalar de qué manera hoy en día se deben repensar los macro conceptos de lectura y de lector y cómo deberían ser abordados tanto por una epistemología que los defina y describa, como por la construcción de una noosfera pedagógica que forme y configure al hombre del siglo XXI. En consecuencia, intentaremos presentar de manera bastante breve y

\footnotetext{
* Conferencia Plenaria de Cierre. V Congreso Internacional de la Cátedra UNESCO Lectura y Escritura. Universidad Pedagógica Experimental Libertador, Caracas, Venezuela. Junio, 2009.
} 
sintética una reforma de las concepciones de lector y de lectura y de qué manera pueden ser tenidas en cuenta dentro de un repensar pedagógico para la formación de lectores de este siglo.

El recorrido a seguir estará enmarcado en lo que hemos denominado 'Hermenéutica para la acción social y educativa'.

"La vida humana es constitutivamente una hermenéutica, una interpretación, una lectura entendida como juego creador con los signos con los cuales damos sentido al mundo y a nosotros mismos" (Larrosa, 1998: 53).

La hermenéutica propuesta intentará resignificar a la lectura y el lector dentro del complejo mundo ciberespacial. Así, se hará una exposición acerca de cómo se lee en la sociedad actual y de qué manera el lector interactúa con los 'cibertextos'. Seguidamente se realizará una reflexión en torno a aspectos relativos a la lectura, al lector y al contexto de lectura, para aportar algunas ideas acerca de una epistemología que pueda dar cuenta de hacia dónde deberían dirigirse las acciones científicas y educativas.

\section{La soledad conectada}

Carlos se levantó muy temprano para ir al colegio. Tiene mucho sueño, pues se acostó a las tres de la mañana haciendo un trabajo para el profesor de biología. El tema: la materia, el volumen y la masa.

Ayer, en su casa, después de clase, almorzó, se acostó un rato y luego se conectó. Abrió varias páginas: el buscador, un foro que encontró sobre el tema, el video juego, el Facebook, el Twitter, una sala de chateo, un blog, un chateo privado con la novia de turno y el servidor de correos electrónicos para escribirles a los compañeros y preguntarles sobre la tarea. Todo esto parece suceder al mismo tiempo.

En el buscador se interna para navegar por las distintas páginas e hipertextos que le ofrecen vinculaciones de todo tipo para el encuentro del tópico que necesita investigar. Navega por las rutas que él mismo ha decido seguir y por los mares, sitios y textos que ha escogido visitar. Carlos conoce cuáles son las rutas seguras y las más científicas desde el punto de vista de la seriedad de la fuente. En su travesía interactúa con algunas páginas en las que puede leer y escribir y así cambiar la información, ampliarla o enriquecer los datos que estas aportan. En esta 'lectura navegada', él dirige el timón de su bitácora en la búsqueda de los temas. La realiza a través de los hipervínculos que le ofrecen los hipertextos. Estos están siempre abiertos para las infinitas rutas de interacción. Para Barrera Linares (2009, en prensa) son "ventanas siempre abiertas hacia el infinito”. En esta búsqueda, Carlos interactúa en soledad dentro del ciberespacio. 
En el video juego, la 'lectura es lúdica', y además estratégica', pues se orienta en la medida en que ya no es eminentemente grafémica, sino multimedia, las imágenes se mueven al antojo y direccionalidad del jugador. Esta ya no es una búsqueda de información, sino una interacción con los otros para el placer y la distracción. Carlos ha entrado en la sociedad enredada.

Al introducirse en el foro, debe registrarse como miembro del mismo para poder interactuar y participar. En este, intenta encontrar en las opiniones y comentarios de los otros foristas, información sobre el tópico. La participación como lector en relación con los modos de interacción 'ciberdiscursiva' es distinta. Es un 'lector crítico' que puede opinar y comentar sobre lo dicho por otros. Al mismo tiempo es lector y escritor. Es un escrilector.

En la sala de chateo se encuadra con otros miembros nativos del ciberespacio, conocidos o no, para interactuar o más bien 'ciberhablar' acerca de las cosas que han sucedido o simplemente para estar conectados. En el chateo lo importante parece ser el sentirse en una noria de interacción comunicativa donde lo fundamental no es lo que se dice, sino saber que el otro está allí, en conexión. No interesa desde dónde se esté conectado, ni la hora de tal encuentro. En el chateo, como 'cibertexto' se ha desarrollado una variedad de lenguaje particular, la 'ciberlingua'. Otra de las particularidades del chateo es que la identidad es discursiva, pues somos lo que decimos ser. Carlos posee una identidad disfrazada.

Seguidamente, se interna en Twitter, el último grito en relaciones sociales ciberespacial. Es lo último de lo último en la Red y, si quieren presumir ante sus familiares y amigos de estar en la cresta de la ola, necesitan una cuenta en Twitter. Es una red social, es decir, una aplicación disponible en Internet cuyos usuarios se relacionan de una forma concreta en una comunidad global de amigos y extraños respondiendo a una simple pregunta: ¿Qué es lo que estás haciendo ahora? La respuesta cargada por supuesto de inmediatez, se puede realizar no solo escribiéndola desde la misma aplicación, sino también mediante mensajes de teléfono, o utilizando un cliente de mensajería instantánea. Como ven, ya se comunica hasta lo que estamos haciendo en el momento en que lo hacemos. Carlos forma parte de la sociedad conectada de comunidades virtuales.

Luego de este navegar por las distintas ciberdiscursividades que le ofrece el ciberespacio, y ante tanta multimodalidad, y multisensorialidad, Carlos ha pasado todo el día solo, acompañado por esa multitud invisible. Son las tres de la mañana, imprime el trabajo y luego de navegar, de linkear, de vincular, de chatear, de bloguear, de twittear, cierra todas las ventanas y se retira a dormir.

La bitácora a la que se ha aludido parece reflejar la vida de un cibernauta. Un individuo para quien el ciberespacio constituye una necesidad vital. Es decir que no puede vivir sin conexión. Estos sujetos habitan siempre el presente, conviven con las pantallas, los $\mathrm{cpu}$, los distintos programas informáticos, las aplicaciones y demás elementos referidos al mundo de la comunicación 
cibernética. Carlos constituye un homo internetus (Fraca de Barrera, 2006a: 47).

Su vida transcurre entre la sociedad real y la sociedad red. Debemos decir que pasan más tiempo en la sociedad red, interconectados con la realidad virtual. ¿Es realmente virtual o real? Que respondan los que tienen hijos 'internautas'.

Asimismo, sabemos que Carlos permanece la mayor parte del tiempo navegando en la soledad conectada. A través de ella y de los recursos informáticos se halla en una plaza pública del tamaño del mundo. Está en la cibersociedad, conectada y enredada. Ciber es un vocablo de origen griego y significa navegación, y la relación entre la navegación real y la virtual es bastante estrecha. Los cibernautas antiguos eran navegantes que para poder mantener la trayectoria de la nave en medio del océano y llevarla a puerto seguro, tenían que calibrarla permanentemente con el movimiento de los vientos, oleajes y tormentas. El internauta contemporáneo, como Carlos, también debe calibrar sus rutas de navegación por el 'ciberespacio' a través de movimientos estratégicos informáticos para poder lograr sus propósitos. Tales movimientos los realiza fundamentalmente mediante la lectura y la escritura.

Así, el cuento de la vida internáutica de Carlos viene a cuenta en relación con lo que he señalado al inicio: detenernos a reflexionar en los aspectos referidos a la lectura en el ciberespacio y a la condición de ciberlector.

\section{Las comunidades ciberdiscursivas}

Permítaseme antes de profundizar nuestra reflexión, recordar unas palabras del lingüista Eugenio Coseriu (1973: 138):

"el lenguaje no puede entenderse, ni describirse fuera de sus relaciones con los individuos hablantes, con su pensar y sus sentimientos, con su ambiente de civilización y cultura, con el momento particular de lo enunciado".

Las comunidades discursivas constituyen un colectivo invisible que interactúa en el en-red-dado mundo del ciberespacio. Están compuestas básicamente por dos tipos de personas: los nativos o habitantes naturales, mayormente jóvenes, para quienes Internet es parte fundamental de su vida personal y cotidiana. Carlos es un ejemplo. Es un nativo ciberespacial. Y por los inmigrantes digitales o informáticos, nosotros, los que hemos vivido la emergencia de Internet y la hemos incorporado de manera parcial a nuestra cotidianidad, mayormente en el campo profesional.

En un estudio realizado en el 2007 por la Fundación Mempo Giardinelli ${ }^{1}$, en Argentina, acerca de la lectura, se indagó sobre la existencia de Internet en los hogares y de su uso. Tal estudio reveló que: 
- $\quad$ En el $48 \%$ de los hogares hay Internet.

- $\quad$ El $38 \%$ dice emplear Internet.

- Al preguntarles para qué navegan en Internet, de los 156 encuestados, el 81\% responde que para enviar o recibir correos electrónicos; el 64\% para chatear; el 17\% para buscar información; el 27\% para bajar música; el 12\% para bajar películas y el 10\% para estudiar.

- Además reveló que se leen pocos libros a través de la pantalla, pero se interactúa con otros formatos textuales como el correo electrónico y el chateo.

Centrándonos en las comunidades discursivas diríamos que nos encontramos ante un colectivo interdiscursivo virtual cuyos parámetros de socialización son distintos a los empleados en el lenguaje no virtual. Dicha interacción, codificada mediante la 'ciberlingua' (Fraca de Barrera, 2006a), está y estará igualmente normada y regulada social y tecnológicamente desde su propia naturaleza, tal y como ocurre en el mundo real. Por lo tanto, Charaudeau (2006: 59) señala:

"todo grupo social es el resultado de la acumulación vivenciada de objetos accionales y de intenciones de lenguaje con sus implicaciones praxiológicas y comunicacionales de las cuales el discurso es a la vez productor y constructor".

Las comunidades ciberdiscursivas no escapan de ello, aun cuando sus implicaciones praxiológicas y comunicacionales sean distintas y particulares.

\section{La lectura a saltos}

Como se evidenció en el pasaje, Carlos, en su navegación, no solo salta de un texto a otro, sino que salta vinculando un texto con otros. Esta lectura parece requerir de unas competencias relativas a la identificación no solo de los aspectos referidos a los grafemas, las palabras y las oraciones, sino a la lectura de palabras-clave. El lector realiza una especie de escaneo, saltando de un párrafo a otro, de un texto a otro, de un vínculo a otro. Para Cerrillo Torremocha (2009) “la mayoría de los usuarios de la red asegura 'leer’ rastreando, es decir, saltándose párrafos o bloques de información”. Tal carrera pareciera efectuarse desde dos lecturas: la secuencial y la vinculante. Esta última se realiza mediante la lectura de unas claves, marcadas generalmente en un color distinto al del texto y que permiten abordar otras latitudes textuales. Para el que lee, pareciera ser más importante el formato del texto y la forma en la cual este se presenta, que las palabras y párrafos que lo componen. Por lo tanto, la conceptualización de la lectura debe profundizarse y no ser simplemente concebida como una actividad intelectual para conocer y comprender, consolidar y analizar los nuevos saberes y deberá ser evaluada bajo 
parámetros distintos. A nuevas necesidades y maneras discursivas de lectura y de leer, nuevas condiciones de lector.

\section{La multidimensionalidad discursiva}

Uno de los aspectos que más resalta de la lectura en la red es la multidimensionalidad textual. De todos es sabido que allí encontramos textos con imágenes (estáticas o en movimiento), textos escritos, hipertextos (los que ofrecen vínculos con otros textos), diferentes medios gráficos para leer (grafemas, números, 'cibergrafos', ideogramas, pictogramas, entre otros), formatos en distintos colores, tipologías textuales particulares y multimedia. Tales elementos ameritan del desarrollo de habilidades de lectura diferentes relativas al nuevo medio, el hipertextual y referidas a las libertades de navegación, de lecturas, de la interactividad, de la virtualidad, de la participación y de la hipervinculación infinita. Ellos imponen entonces una sociología del lector y de sus procesamientos cognoscitivos de distinto tipo, y un nuevo tratamiento epistemológico para el conocimiento de la lectura y del cómo se lee. Dichas habilidades se refieren fundamentalmente y se encuentran ligadas a la alfabetización ¿Cuál debe ser la alfabetización en el siglo XXI? ¿Debemos seguir enseñando a leer y a escribir a partir de la seguidilla silábica, del dictado de palabras y de la copia o debemos armar a nuestros estudiantes con herramientas discursivas y ciberdiscursivas de carácter textual e hipertextual, que les permitan ser lectores de este siglo? La discusión al respecto ha sido dada en algunas mesas de trabajo del V Congreso de la Cátedra UNESCO para la lectura y la escritura, realizado en Venezuela en junio de 2009, y proporcionarán buenas respuestas para el campo educativo. Pero de lo que sí estamos seguros es de que la escuela en ese sentido, debe reorientar sus propuestas curriculares y abordar la situación con mayor fuerza y menos indiferencia.

\section{La condición textual}

Las investigaciones dentro de la lingüística del texto y del análisis del discurso han definido al texto y al discurso desde diversas perspectivas. Molero de Cabeza (2006: 16) precisa que "el discurso como noción es muy 'ambiguo', pues puede referirse a texto, a formas del lenguaje, como suceso de comunicación o como interacción verbal”. Dentro del contexto ciberespacial, es concebido como una interacción comunicativa multimodal, interactiva, dinámica, fluida y multisensorial. Debemos señalar que la interacción textual en el ciberespacio ha enriquecido el espectro discursivo con la llegada de novedosos formatos textuales como el chateo, las redes sociales, los videojuegos, los foros, el correo electrónico, los weblogs, los libros electrónicos en los cuales las condiciones propuestas para definir a los textos convencionales parecieran ser insuficientes. Por ejemplo, la interactividad, la intercomunicación, la ruptura de los roles de 
emisor y receptor, los de lector y de escritor, la autoría y los derechos de autor, así como la propia concepción de texto, contexto y cotexto, los referentes presentes en ellos, la escrilectura, entre otros. Asimismo, la cibertextualidad no deberá ser entendida como una extensión ni de la teoría lingüística, ni discursiva, ni de la teoría literaria. Debe ser concebida a partir de una nueva epistemología que la contemple en toda su multidimensionalidad, particularidad y especificidad. Por lo tanto, proponemos considerar, entonces la noción de 'etnocomunicación digital' o 'ciberantropología de la comunicación' como campo del conocimiento que estudie lo relativo a la intercomunicación en el mundo virtual. Se requiere, además repensar la condición de textualidad y de discursividad y en este sentido, una 'teoría etnocomunicativa del ciberespacio' tendrá la palabra.

\section{La ciberdiscursividad es escritura}

Hasta la democratización del ciberespacio, la lectura se realizaba mayormente a través de textos paginados, leídos básicamente para informar, instruir o distraer. La comunicación se realizaba en una interacción referida a la construcción de significados que hacía el lector a través de su conocimiento previo y de los datos que aportaba el texto. Dicha comunicación se ampliaba, cuando mucho, a un intercambio silencioso con las ideas del autor por glosas escritas a pie de página o en los márgenes del libro. Éramos fundamentalmente lectores mudos.

Con la llegada de Internet y de la www, mediante un programa de interconexión, dejamos ya de ser lectores sin palabras. Ello significa que la condición de lector y de lectura han cambiado, pues ya se puede manipular el texto, interactuar con los autores, si la conectividad lo permite, y dar nuestra opinión al resto del mundo acerca de lo que leemos y escribimos. Es decir, que lo importante es la comunicación y más específicamente la intercomunicación que es fundamentalmente escrita, de lectores y de escritores. Berners-Lee, inventor de la www, en una entrevista realizada en el mes de abril de este año ha señalado que "el desarrollo de la web 3.0 traerá una intercomunicación mundial sin precedentes en las que las barreras de idioma serán derribadas"2. Al respecto preguntamos ¿La 'ciberlingua' se convertirá en una especie de 'ciberlingua' franca o 'ciberesperanto'?

\section{El lector y el ciberlector}

Con el advenimiento de la imprenta en 1450, se dice que Gutenberg democratizó al libro, pues este se masificó y llegó a los ojos de todo el mundo. De igual modo, se expresa que con la llegada de las telecomunicaciones, la información se democratizó y llegó a todo el mundo conectado. Atención: conectado. Internet también ha cambiado nuestra forma de ver el mundo y de concebirlo, para bien y para mal. Estamos en la sociedad de la información y de la comunicación. 
Lo importante entonces es saber manejar inteligentemente la información a través de la intercomunicación. ¿Qué significado tienen tales palabras para la condición de lector en la sociedad actual? "El lector latinoamericano es una mujer joven, con alto nivel de escolaridad y elevados ingresos, que vive en una ciudad grande", refiere un diario con motivo de una investigación realizada en Latinoamérica para el día del libro y del idioma. Sin embargo, tales características no se corresponden con Carlos, nuestro personaje referencial. Tal estereotipo pareciera responder a la pregunta: ¿Quiénes leen, compran y consumen libros de literatura? En la biblioteca universal virtual se pueden encontrar tipologías de libro y de lectores que no corresponden con la caracterización aludida. Obviamente que el mundo de la lectura es más ancho y ajeno. Sabater (2004: 7) plantea que "la lectura nos ayuda a prepararnos para las decisiones que vamos a tener que tomar en cuenta a lo largo de nuestra vida". Y Saramago (2006: 90-91) por su parte, acota "Leyendo se acaba sabiendo casi todo. Yo también leo. Por tanto algo sabré... No sirve la misma forma para todos, cada uno inventa la suya, la suya propia". El foco de acción estaría dado en la selección de los materiales de lectura, en la comprensión de textos y de cibertextos de cualquier tipo y de los mecanismos cognoscitivos que el lector estratégico realiza para construir su propia forma de leer.

Asimismo, Cerrillo Torremocha (2009) precisa que hoy en día se debe hablar de dos tipos de lectores:

- El lector tradicional concebido como un sujeto que lee libros, es un lector competente, literario, que además, se sirve de los nuevos modelos de lectura, como los de Internet.

- El lector nuevo es un consumidor fascinado por las nuevas tecnologías, enganchado a la red, que se comunica con los otros, pero que no es un lector de libros, ni lo ha sido antes. Generalmente constituye la generación Internet y son jóvenes en su mayoría.

Por otra parte, si se asume que la lectura y el leer son actos voluntarios, ambos lectores (el tradicional y el nuevo) han escogido sus rutas de lectura y son también libres en la selección de los materiales que leen.

\section{Los caminos por recorrer}

La breve reflexión a la que se hizo referencia anteriormente invita a una revisión y resignificación de las nociones de lectura y de lector básicamente en dos campos del conocimiento: el científico y el pedagógico. En lo educativo, solo se expondrán algunos fundamentos de un modelo pedagógico estratégico en validación, al cual me referí en la instalación de las Jornadas de la Cátedra UNESCO en noviembre de 2007. En cuanto al científico, abordaré algunas ideas sobre la reconceptualización de la lectura y del lector dentro del ciberespacio. 


\section{Algunas ideas pedagógicas}

La educación es la formación para la vida en una sociedad determinada. En el entorno específicamente universitario, el modelo pedagógico estratégico integrador que proponemos, tiene el propósito de desarrollar en los estudiantes una inteligencia lingüística estratégica y la formación de un individuo con unas competencias psicosociolingüísticas para resolver inteligentemente situaciones comunicativas verbales, necesarias para la humana convivencia en la sociedad real y en la sociedad red.

La didáctica estratégica como la que se propone en este modelo se concibe como la puesta en práctica de actividades (áulicas o no) relativas a la lectura, a la escritura, al hablar y la escucha estratégicos. Incluiría, además el desarrollo de una aptitud psicosociolingüística estratégica para tratar de resolver problemas de comunicación, oral, escrita y ciberlingüística, mediante el pensamiento y la conciencia del estudiante universitario. De aquí surge, entre muchas, la siguiente interrelación dialógica compleja:

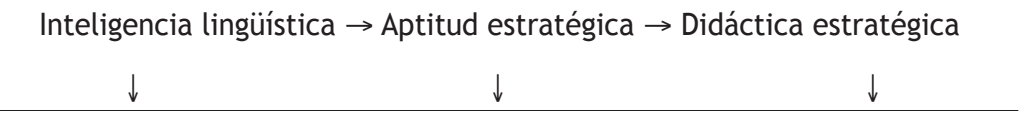

En esta dialógica, la inteligencia lingüística requeriría necesariamente del desarrollo de competencias discursivas orales, escritas y ciberdiscursivas, de orden social, psicológico y lingüístico desde una orientación didáctica de carácter estratégico.

La estrategia es definida por Morin (1998: 265) como:

"el método de acción propio de un sujeto en situación de juego, en el que, con el fin de lograr sus fines, se esfuerza por sufrir al mínimo y emplear el máximo de las reglas, las incertidumbres y los azares del juego".

Es decir, la estrategia necesita de competencia e iniciativa para actuar y vencer. Requiere de una inteligencia estratégica. Es un accionar, un actuar inteligentemente. Es determinar el qué, el porqué, el para qué y el cómo de nuestras acciones, esencialmente comunicativas.

De tal manera pues, que lo más importante dentro de entorno escolar y universitario es la noción de docente, de alumno y de las acciones estratégicas que se realizan en el quehacer áulico. Ello significa que deben inventar e inventarse en cada clase y en cada curso, a partir de la reflexión y de la toma de conciencia sobre su hacer y su actuar. De este modo, un profesor universitario, por ejemplo, deberá propiciar en sus alumnos el desarrollo de sus competencias relativas a la 
inteligencia lingüística de su lengua materna oral, escrita y ciberlingüística. Asimismo, deberá crear sus propias representaciones acerca de la pedagogía y de la didáctica y permitir que sus estudiantes también las inventen. Es indagar en sus alumnos acerca de sus creencias y experiencias en relación con la utilidad de la lectura y de la escritura en entornos reales y virtuales, y en el placer que significa encontrar el goce estético a la literatura y a la 'ciberliteratura'. Es simplemente, dejar que los estudiantes creen sus propios juegos estratégicos e inventen los medios más idóneos para su propio aprendizaje, cuestión que ya realizan en la interacción virtual. En este juego estratégico, el docente orientaría la reflexión sobre ese andar aprendiendo a aprender, a jugar estratégicamente, como lo recomienda Morin (1998).

\section{La nueva dimensión científica de la lectura y del lector}

Como ya se ha señalado, las nociones referidas al texto, al lector, al contexto y a la propia noción de discurso deben ser reformuladas en sus planteamientos. Sugerimos hacerlo con una actitud científica distinta. Adoptar la transisciplinariedad y la interdisciplinariedad como caminos epistemológicos, pues dicho universo plantea necesariamente implicaciones de diverso tipo: psicológicas, sociales, culturales, informáticas, éticas, entre otras, que requieren de tal reorientación. Asimismo, el desarrollo de ese mundo paralelo está derivando en cambios biológicos, psicológicos, sociológicos y técnicos en la sociedad y en la cultura que no pueden ser explicados solo desde la simplicidad de las disciplinas. Giovanni Parodi, en un reportaje realizado por el diario El Mercurio de Chile (17 de mayo de 2009), en relación con la lectura en la pantalla hace hincapié en la cantidad de variables que condicionan el proceso de lectura:

"muchas de ellas no indagadas científicamente aún, como por ejemplo la motivación, los conocimientos previos, la edad, el nivel de escolarización, la extensión del texto, el tipo de organización lingüística y la retórica de la información”"

Creemos que su abordaje implica algo más que el señalamiento del objeto de estudio, el desarrollo de un método de análisis para describirlo y de un cuerpo de conclusiones que lo atrapen y compartimenten. Barrera Linares (2009) señala asimismo que:

"la emergencia de las comunidades virtuales ha traído consigo una serie de nuevas variables que habrían de ser tomadas en cuenta a la hora de teorizar sobre el hombre y sus facultades comunicativas".

El mundo científico, creemos, debe abordar el estudio de la 'ciberdiscursividad' desde las nociones y espacios en los cuales esta ocurre y estudiarla desde sus propias esencias, concebidas desde una verdadera y seria ciberantropología de la comunicación mediada por el computador. 


\section{La lectura y el lector. Una propuesta de conceptualización}

Leer en papel es una operación muy diferente de la lectura en pantalla: mucho más de lo que podría parecer. Esto significa que se han producido cambios en los modos de buscar, de encontrar, de acceder a la información y obviamente, de procesarla. Tales transformaciones han impregnado todos los ámbitos del espectro humano: el biológico, el social, el cognoscitivo, y esencialmente, el comunicativo e intercomunicativo.

Desde la dimensión biológica, por ejemplo, se han producido cambios en el funcionamiento hemisférico. Ya no podemos decir que el procesamiento lingüístico se realiza exclusivamente en las zonas ubicadas en el hemisferio izquierdo. La lectura multimodal y multisensorial requiere de la confluencia de ambos hemisferios para la obtención de la información y la construcción de conocimientos. La neurociencia y los estudios neurológicos deben tomar en consideración este fenómeno y estudiar las funciones interhemisféricas encargadas de la lectura más allá de las localizadas en el hemisferio izquierdo.

Asimismo, las habilidades cognoscitivas referidas a la lectura de grafemas, también deben considerar la lectura de números con valores distintos, los pictogramas, el empleo de signos de puntuación con funciones figurativas (recordemos los emoticones), las marcas 'ciberdiscursivas' referidas a los 'cibergrafos', la pérdida de la escritura de vocales y el consecuente descifrado de los mismos a partir del nombre de la letra y no de su pronunciación. Tales aspectos, codificados en la 'ciberlingua' (Fraca de Barrera, 2006a) ameritarían de descripciones distintas, de un procesador de información, y de un lector con habilidades cognoscitivas más allá de un descifrador de grafemas, de palabras y de un constructor de significados codificados en textos escritos. Creemos que debe comenzar a verse y estudiarse como una forma de comunicación, de conexión y de interactividad, fluida, dinámica, veloz, en donde juegan un papel fundamental las estrategias y las habilidades de orden psicológico, social, organizacional y tecnológicas que el nuevo lector pone en práctica en su convivencia internáutica. Por lo tanto, como lo ha señalado Fraca de Barrera (2006b) la 'ciberpsicolingüística', deberá tener que redimensionar sus vías de investigación sobre el procesamiento de la información cibertextual.

Desde la perspectiva social, con la irrupción de la comunidades virtuales, el intercambio y la interacción social deben verse desde una perspectiva menos simplista que las de preferir quedarse conectados que verse cara a cara, a pesar del tiempo y las distancias. Ya Ludwig Wittgenstein (1958: 421) lo había ratificado al señalar que "el lenguaje es como una máquina en funcionamiento que realiza su trabajo. Y es de naturaleza social por cuanto su uso está determinado por una sociedad específica". A nuestro modo de ver se está desarrollando una nueva interacción social, cuyas consecuencias no podemos predecir pero que cambiarán nuestras maneras de relacionarnos, y cambiarán el lenguaje. Uno de los aspectos que más nos llama la atención en este sentido, son las características de las comunidades que habitan el ciberespacio: la identidad 
disfrazada, la horizontalidad en las relaciones, la cortesía y formas de tratamiento, la interactividad, la velocidad y el dinamismo en la fugacidad de la relaciones, las nociones de temporalidad y de espacialidad y de otros tantos aspectos, positivos y negativos que ameritarían de una incursión transdisciplinaria ciberespacial de otro tipo.

Por último, y la más importante, las interacciones comunicativas en la red han traído el desarrollo de nuevos formatos discursivos: los foros, el chateo, el correo electrónico, los weblogs, las redes sociales y otros por venir. Ellos plantean un estudio más allá de los propiamente discursivos que involucren lo esencialmente lingüístico y verbal. Por ejemplo, las nociones de emisor y de receptor, la lectura y la escritura, la escrilectura y de otros aspectos de la ciberdiscursividad.

\section{Hacia una tipología de lector}

Si retomamos la breve historia de Carlos, diríamos que la característica fundamental de un lector de nuestros días y de los venideros es la condición de estratega. Al respecto Morin, señala que la inteligencia estratégica radica en:

"una aptitud general del ser humano, que le permite tratar y resolver problemas particulares y diversos en situación de complejidad y que alcanza su máxima expresión en el pensamiento y la conciencia” (Morin, 2006: 43).

Asimismo, consideramos que el lector estratega para la realización de su travesía de lectura toma en cuenta los siguientes aspectos:

- Identifica el contexto de comunicación y de intercomunicación y sus rutas de acción, ya sean textuales, hipertextuales o de otro tipo.

- Conoce y determina intencionalmente los propósitos de la lectura.

- Reconoce los diversos órdenes discursivos y ciberdiscursivos, así como las organizaciones textuales y 'cibertextuales'.

- Determina el conocimiento previo sobre el tema del texto, antes de la lectura y los va controlando cuando lee.

- Elabora inferencias a medida que va leyendo.

- Controla y regula su procesamiento cognoscitivo en función de los propósitos de la lectura y de las vinculaciones a que haya lugar en sus rutas de navegación 'hipertextual'.

- Asimila e integra a su teoría del mundo compartido los significados construidos a través de la interacción con los textos y los cibertextos. 
- Emplea la lectura para fines comunicativos y de interacción discursiva más allá de la construcción de significaciones que le ofrecen los textos.

- Infiere los rasgos 'posibles o previsibles' de los otros cibernautas que serán sus interlocutores, en atención a la web en la que se adentra.

Todo lo anterior precisa de un lector estratega y multidimensional. Ello significa que realiza diversas lecturas y construye significados de distinto tipo a partir de diferentes modos de leer. Emplea la lectura multimodal; la lectura vinculante (a través de los hipervínculos); la lectura interactiva en los foros; en los weblogs y en las redes sociales (Facebook, Twitter, Youtube); la lectura crítica al participar como comentarista, al acotar alguna opinión en un foro; la lectura multisensorial, realizada mediante la interacción de diferentes sentidos y modos de leer en diversos formatos; una lectura colectiva en la medida en que desde la conexión realiza interpretaciones, con otros lectores de la red. De tal manera pues, que la condición de lector de la red o el 'ciberlector' requiere del desarrollo de competencias para actuar de manera efectiva en la sociedad del conocimiento. Es un lector estratega que sabe manejar sus propósitos de lectura, sabe cómo encontrar la información que requiere, conoce y emplea los recursos informáticos y discursivos que le ofrece la red. Se podría decir que es un 'letrado digital'. En consecuencia, la alfabetización inicial deberá ir más allá de lo funcional y discursivo, al menos cómo han sido entendidos hasta el presente.

De acuerdo con ello, el lector como homo legens haría un recorrido por los diversos formatos textuales en relación con sus propósitos de lectura. Hablaríamos de un lector navegante o vinculante, hipertextual, crítico, lúdico, científico, literario, académico, evaluador, corrector, entre otros. Asimismo, en la ciberdiscursividad, la relación especular que se establecía entre el autor y el lector ya no existe, pues la nueva noción de lectura y de lector ha atravesado el espejo. Cavallo y Chartier (2001: 16) nos recuerdan en su libro sobre la Historia de la Lectura que "un texto está revestido de un significado y de un estatuto inéditos cuando cambian los soportes que le impone a la lectura".

El individuo de la sociedad latinoamericana y universal del siglo XXI, deberá enfrentarse con retos nuevos y de otra índole en los cuales tiene mucho que ver su condición de lector. Entre ellos los siguientes:

1. La competitividad y la empleabilidad se asocian con la capacidad que tienen las personas de participar activamente en su sitio de trabajo y promover procesos de innovación.

2. En la sociedad del siglo XXI, la ciencia y la tecnología juegan un papel cada vez más importante, incluso en el desarrollo de actividades de ocio, arte, deporte y recreación. 
3. Los grandes problemas sociales de nuestro tiempo tienen en general un trasfondo científico y tecnológico. Se requieren ciudadanos que puedan participar con conocimiento de causa en los debates y en la toma de decisiones que los atañen.

4. El mundo actual requiere de ciudadanos con sentido crítico, capaces de preguntarse sobre el sustento de algunas afirmaciones y de buscar autónomamente información para formarse una opinión racional y sustentada 4 .

\section{A modo de cierre de esta apertura}

Vivimos en un mundo complejo, donde la incertidumbre, el azar, el caos y lo convulso caracterizan nuestra cotidianidad. Nada parece permanecer. El presente es el ahora, el estar y la conexión. El mundo ciberespacial es una muestra de ello. Los valores culturales están siendo configurados por la velocidad, la instantaneidad y la interactividad como medios de comunicación de unos tiempos no solo reales, sino fundamentalmente virtuales. La virtualidad y la intercomunicación cohabitan con el mundo real. Por lo tanto, resulta imperioso verlos, desde una dialógica compleja que los vincule en sus antagonismos, sus correspondencias y sus complementariedades, entenderlos desde una actitud transdisciplinaria en las dimensiones teórica, investigativa y educativa.

El lector en la sociedad actual, de acuerdo con sus estrategias de lectura navega por los confines del ciberespacio y se pasea por los libros enrollados en formato digital o por las páginas del libro impreso. Así, vincula los textos impresos con los chateos, los foros, las redes sociales, los hipertextos y los apuntes escolares en una especie de híbrida convivencia familiar, social e internáutica. La vida de la lectura y del lector ya no es la misma, se encuentra entre los ojos y la pantalla en una soledad conectada, plena de identidades disfrazadas. Son otros tiempos.

Abordar el estudio de este mundo aparte y familiar a la vez, organizado y caótico, lleno de incertidumbre y de azar, de redes amigas y enemigas, de todo lo que dibuja, desdibuja y configura al hombre contemporáneo, será un reto importante no solo para la formulación de teorías comunicativas futuras, sino también para la reorientación de la educación, que hemos asumido como estratégica, para la formación de la inteligencia lingüística de los hablantes, escritores y escrilectores. Así pues, los teóricos, epistemólogos, científicos y educadores tienen la palabra para comenzar a andar caminos nuevos y de distinto orden. 


\section{REFERENCIAS BIBLIOGRÁFICAS}

Barrera Linares, L. (2009, en prensa). Habla pública, Internet y otros enredos literarios. Caracas: Editorial Equinoccio. Universidad Simón Bolívar.

Cavallo G. \& Chartier, R. (2001). Historia de la lectura. Madrid: Alfaguara. Col Taurus.

Cerrillo Torremocha, P. (2009). Los nuevos lectores. La formación del lector literario. Biblioteca virtual Cervantes [en línea]. Disponible en: http://www.cervantesvirtual.com

Charaudeau, P. (2006). Lenguaje, acción, poder. De la identidad social a la identidad discursiva del sujeto. En L. Molero de Cabeza, A. Franco \& L. Vieira (Eds.), Estudios del discurso en Venezuela. Teoría y método (pp. 51-70). FONACIT y FUNDACITE-Zulia.

Coseriu, E. (1973). Lingüística general. Madrid: Gredos.

Fraca de Barrera, L. (2006a). La ciberlingua. Una variedad compleja de lengua en Intenert. Caracas: Vicerrectorado de Investigación y Postgrado UPEL-IVILLAB.

Fraca de Barrera, L. (2006b). Los estudios psicolingüísticos en Venezuela: Un devenir desde la oralidad a la escritura. Lingua Americana, Año X, 19, 29-36.

Fraca de Barrera, L. (2007). Hacia la configuración de modelo pedagógico estratégico integrador. Conferencia I Jornadas de la Cátedra UNESCO. Caracas. IVILLAB-UPEL.

Fundación Mempo Giardinelli (2007). Primera encuesta de lectura de área metropolitana Gran Resistencia [en línea]. Disponible en: http: / /www.fundamgiardinelli.org.ar

Larrosa, J. (1998). La experiencia de la lectura. Barcelona: Alertes.

Molero de Cabeza, L. (2006). El enfoque semántico-pragmático en el análisis del discurso: Retrospectiva de los últimos 25 años en la Universidad del Zulia. En L. Molero de Cabeza, A. Franco \& L. Vieira (Eds.), Estudios del discurso en Venezuela. Teoría y método (pp. 17-32). FONACIT y FUNDACITE-Zulia.

Morin, E. (1998). El Método IV. Las ideas. Madrid: Cátedra.

Morin, E. (1999). Con la cabeza bien puesta. Buenos Aires: Nueva Visión.

Morin E. (2006). EL Método V. La humanidad de la humanidad. Madrid: Cátedra.

Sabater, F. (2004). Los intelectuales, la democracia y la educación. Entrevista. Acción Pedagógica, 13(1), 4-7.

Saramago, J. (2006). La caverna. México: Punto de Lectura.

Wittgenstein, L. (1988). Investigaciones filosóficas. Ediciones de la UNAM. 


\section{NOTAS}

${ }^{1}$ Informe que puede encontrarse en www.fundamgiardinelli.org.ar (20-02-2009).

${ }^{2}$ Diario Primera Hora, 23 de abril de 2009.

${ }^{3}$ www.diario.elmercurio.com (17-05-2009).

${ }^{4}$ http://www.educoas.org/Portal/boletin/es/Es_AnuncioTema551LD.html 